\title{
Type III Hyperlipoproteinemia Associated with Apolipoprotein E Phenotype E3/3 Structure and Genetics of an Apolipoprotein E3 Variant
}

\author{
Stanley C. Rall, Jr., Yvonne M. Newhouse, Howard R. G. Clarke, Karl H. Weisgraber, Brian J. McCarthy, Robert W. Mahley, \\ and Thomas P. Bersot \\ Gladstone Foundation Laboratories for Cardiovascular Disease, Cardiovascular Research Institute, Departments of Pathology and \\ Medicine, University of California, San Francisco, California 94140-0608
}

\begin{abstract}
A family has been described in which type III hyperlipoproteinemia is associated with apo $E$ phenotype E3/3 (Havel, R. J., L. Kotite, J. P. Kane, P. Tun, and T. Bersot. 1983. J. Clin. Invest. 72:379-387). In the current study, the structure of apo $E$ from the propositus of this family was determined using both protein and DNA analyses. The propositus is heterozygous for two different apo $\mathrm{E}$ alleles, one coding for normal apo E3 and one for a previously undescribed variant apo E3 in which arginine replaces cysteine at residue 112 and cysteine replaces arginine at residue 142. Apo $E$ gene analysis of nine other family members spanning four generations indicated that only those five members having type III hyperlipoproteinemia possess the variant apo E3. Like the propositus, all five are heterozygous for this variant, suggesting that the disorder in this family is transmitted in a dominant fashion. The variant apo $\mathrm{E3}$ was defective in its ability to bind to lipoprotein receptors, and this functional defect probably contributes to the expression of type III hyperlipoproteinemia in this family.
\end{abstract}

\section{Introduction}

Type III hyperlipoproteinemia is a genetic disorder of lipoprotein metabolism that predisposes affected individuals to the development of premature atherosclerosis (1). The most distinctive clinical feature of the disorder is the presence of a particular type of xanthoma in about half of type III subjects. These xanthomas of the palmar creases, xanthoma palmaris striata, have not been described in any other disorder. The major biochemical feature of type III hyperlipoproteinemia is the accumulation in the plasma of $\beta$-VLDL, which are cholesteryl ester-rich remnants of both hepatic and intestinal origin $(2,3)$. Thus, the error in lipoprotein metabolism in type III subjects appears to be impaired removal of chylomicron and VLDL remnants from the plasma. In addition to the abnormality in lipid composition, $\beta$-VLDL also have an abnormal protein composition in that the concentration of apo $E$ is greatly increased (4) compared with that in the normal, pre- $\beta$ migrating VLDL.

The major genetic defect in type III subjects is the occurrence of a mutant form of apo $E$ that does not bind normally to

Address correspondence to Dr. Stanley C. Rall, Jr., Gladstone Foundation Laboratories, P. O. Box 40608, San Francisco, CA 94140-0608.

Received for publication 29 August 1988 and in revised form 23 November 1988.

J. Clin. Invest.

(c) The American Society for Clinical Investigation, Inc.

0021-9738/89/04/1095/07 \$2.00

Volume 83, April 1989, 1095-1101 lipoprotein receptors $(5,6)$. The polymorphism of apo $\mathrm{E}$ is due to the existence of multiple alleles at a single gene locus $(7,8)$. The three major alleles code for apo $\mathrm{E}$ isoforms (termed E4, $\mathrm{E} 3$, or E2, based on their isoelectric focusing position) and give rise to six apo $\mathrm{E}$ phenotypes (9), three homozygous (E4/4, $\mathrm{E} 3 / 3, \mathrm{E} 2 / 2)$ and three heterozygous (E4/3, E3/2, E4/2). The three apo $\mathrm{E}$ isoforms differ from one another by single amino acid substitutions $(10,11)$. An arginine-for-cysteine substitution at residue 112 differentiates apo E4 from the most commonly occurring form, apo E3, while a cysteine-for-arginine substitution at residue 158 differentiates apo E2 from apo E3. The substitution at residue 158 in apo E2 yields a protein that binds defectively to lipoprotein receptors, having only about $1 \%$ of the normal activity (12). Type III hyperlipoproteinemia is almost invariably associated with the phenotype E2/2. However, while $\sim 1 \%$ of all individuals are phenotype E2/2, only $\sim 2-10 \%$ of those E2/2 individuals actually develop type III hyperlipoproteinemia $(13,14)$. This indicates that type III hyperlipoproteinemia is a multifactorial disorder $(13,14)$; nevertheless, the primary molecular defect lies within apo E.

In 1983 Havel et al. (15) described a family of Salvadoran origin with type III hyperlipoproteinemia that included the typical characteristics, such as palmar xanthomas, $\beta$-VLDL, and approximately equal elevations of plasma cholesterol and triglycerides. A complete lipoprotein analysis was also presented. However, the type III hyperlipoproteinemia in this family was also unusual in several respects. First, several teenage family members had pronounced hyperlipidemia, which in type III hyperlipoproteinemia rarely occurs before adulthood, especially in women. Second, all family members, including the affected subjects, were apo E phenotype E3/3. Based on their findings, Havel et al. (15) suggested that the affected family members had at least one allele coding for a heretofore unrecognized abnormal form of apo E. In this report we describe the structure and receptor binding activity of this unusual variant and the genetics of apo $E$ in four generations of this family.

\section{Methods}

Subject description. Havel et al. (15) provided a medical history for three generations of A. family members in 1983 . The family members have been followed clinically at regular intervals since that time. The current study involved 10 members of the A. family: all 8 described by Havel et al., plus 2 fourth-generation subjects. An updated pedigree of the A. family, indicating the distribution of type III hyperlipoproteinemia, is presented in Fig. 1.

Protein analysis. Apo E was isolated from the $d<1.02 \mathrm{~g} / \mathrm{ml}$ fraction of lipoproteins from the propositus and several other family members by previously described techniques $(10,11)$. For $\mathrm{CNBr}$ digestion, column-purified apo E (10) was incubated with a 30-fold excess of $\mathrm{CNBr}$ (Pierce Chemical Co., Rockford, IL) in $70 \%$ formic acid 


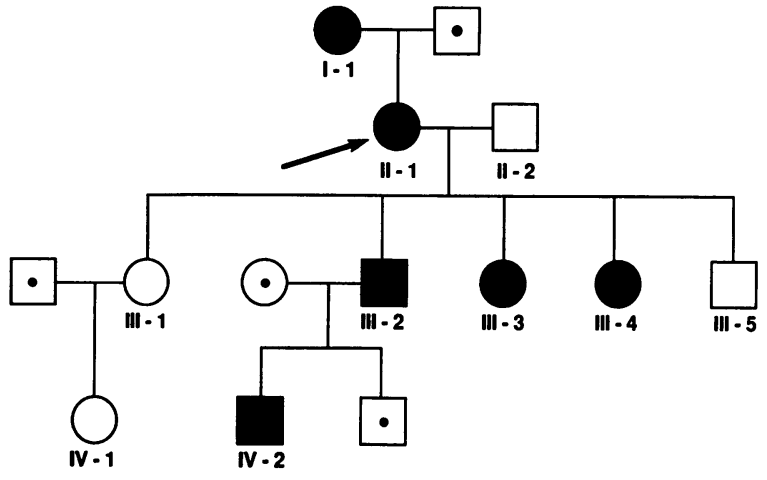

Figure 1. Pedigree of the A. family. The arrow denotes the propositus. The subject designations are those used by Havel et al. (15). ०, $\square$, unaffected family members; $\bullet, \bullet$, family members with type III hyperlipoproteinemia; $\odot, \sqcup$, family members not tested.

for $28 \mathrm{~h}$ at room temperature. After dilution with $\mathrm{H}_{2} \mathrm{O}$ and lyophilization, the digested protein was dissolved in $20 \%$ formic acid and applied to a Sephadex G50 column to isolate the largest $\mathrm{CNBr}$ peptide $(10,11)$. For tryptic digestion the apo $\mathrm{E}$ was first carboxymethylated with iodoacetic acid (Sigma Chemical Co., St. Louis, MO). After reduction overnight in a twofold molar excess of DTT in $6 \mathrm{M}$ guanidine, $0.1 \mathrm{M}$ phosphate, pH 8.2, under an $\mathrm{N}_{2}$ atmosphere, a 20-fold molar excess of iodoacetic acid was added. After $30 \mathrm{~min}$ in the dark the reaction mixture was dialyzed against $5 \mathrm{mM} \mathrm{NH} \mathrm{mCO}_{3}$ and lyophilized. Digestion with trypsin (Sigma Chemical Co.) was performed in $5 \mathrm{mM}$ $\mathrm{NH}_{4} \mathrm{HCO}_{3}$ at an enzyme-to-substrate ratio of $1: 25$ for $3 \mathrm{~h}$ at $37^{\circ} \mathrm{C}$. After lyophilization, peptides were separated by high-voltage paper electrophoresis at $\mathrm{pH} 6.4(2 \mathrm{~h}, 3 \mathrm{kV})$ and, if needed, a second run at $\mathrm{pH}$ $1.9(1.5 \mathrm{~h}, 3 \mathrm{kV})(11)$.

Analytical protein methods, including isoelectric focusing, amino acid analysis, and peptide sequencing, were carried out as described (10). Receptor binding assays of isolated apo $\mathrm{E} \cdot$ dimyristoylphosphatidylcholine (DMPC) ${ }^{1}$ complexes were carried out with cultured human fibroblasts using ${ }^{125}$ I-labeled LDL as the competitor (16).

DNA cloning. Genomic DNA was extracted from white blood cells of the propositus, and a genomic library was constructed in the $\lambda$ FIX vector (Stratagene, La Jolla, CA). Genomic DNA was partially digested with Bam HI restriction endonuclease (New England Biolabs, Beverly, MA) according to the supplier's directions. The digested DNA was size-fractionated on 10-40\% sucrose gradients and analyzed on $0.4 \%$ agarose gels, and fractions in the 9- to 22-kb pair ( $\mathrm{kbp}$ ) size range were pooled, dialyzed for $50 \mathrm{~h}$ against $200 \mathrm{vol}$ of $10 \mathrm{mM}$ Tris (pH 7.5), 1 mM EDTA, and subsequently precipitated by ethanol. The Bam HIdigested insert DNA was partially filled in at the $5^{\prime}$ protruding ends with dATP and dGTP, ligated into $\lambda$ FIX, packaged into Gigapack Gold (Stratagene), and titered on Escherichia coli LE392 and P2392 according to the supplier's directions. Approximately 750,000 phage plaques, grown on P2392, were screened essentially as described (17) with a randomly primed ${ }^{32} \mathrm{P}$-labeled (18) Ava I-Hin fI restriction endonuclease fragment purified from a previously characterized cDNA clone of human apo E mRNA (19). Five individual recombinant bacteriophages were identified, and DNA was extracted from plaque-purified isolates.

Bacteriophage recombinant DNA was digested with a variety of restriction endonucleases (Bethesda Research Laboratories, Gaithersburg, MD, and New England Biolabs) according to the suppliers' directions and was then examined by electrophoresis on $0.8 \%$ agarose gels. The Sac I-digested DNA (New England Biolabs) was transferred to

1. Abbreviations used in this paper: DMPC, dimyristoylphosphatidylcholine; kbp, kilobase pair. nitrocellulose (Schleicher \& Schuell, Keene, NH) by blotting (20), hybridized to the ${ }^{32} \mathrm{P}$-labeled apo $\mathrm{E}$ cDNA probe, and examined by autoradiography to identify the apo $\mathrm{E}$ gene fragments. A 4.8-kbp Sac I fragment (21) was identified by hybridization and subsequently isolated from low melting-point agarose using the Geneclean method (Bio 101 Inc., La Jolla, CA). The purified fragment was subcloned into the Bluescribe M13(+) plasmid (Stratagene), and apo E gene-containing recombinants were identified by restriction digest analysis on agarose gels. Recombinant plasmids were digested with Pst I (New England Biolabs) and subcloned into M13 mp19. Appropriate clones containing a 174-bp Pst I apo E gene fragment (21) were identified by restriction digest analysis as described above. The apo $E$ gene DNA inserts in M13 were sequenced by the dideoxynucleotide chain termination method of Sanger et al. (22).

Genomic DNA analysis. Genomic DNA was prepared from the total blood cell pellet obtained by centrifugation of EDTA-treated blood (23). The 4.8-kbp Sac I fragment, which is described above and contains the region of the apo $\mathrm{E}$ gene corresponding to cysteine-arginine interchanges at residues 112 and 142 in the protein, was used as a control to establish the hybridization conditions of the various probes. The DNA from subjects with either the E4/4, E4/3, or E3/3 phenotypes served as additional controls for the cysteine-arginine interchange at residue 112 . Oligonucleotide probes and primers were synthesized by the methoxyphosphoramidite method on a synthesizer (model 380B; Applied Biosystems, Foster City, CA). Probes were purified by PAGE and primers by the oligonucleotide purification cartridge system (Applied Biosystems). Probes were labeled with $\left[\gamma-{ }^{32} \mathrm{P}\right] A T P$ using polynucleotide kinase $(24)$ to $\sim 2 \times 10^{6} \mathrm{cpm} / \mathrm{ng}$. Four oligonucleotide probes, all 19-mers from the noncoding strand, were used: Arg-112, nucleotides 3,754-3,736; Cys-112, nucleotides 3,754-3,736, but with the tenth base changed from guanine to adenine; Arg-142, nucleotides 3,844-3,826; and Cys-142, nucleotides $3,844-3,826$, but with the tenth base changed from guanine to adenine. A fifth 19-mer was made from the coding strand: Arg-158, nucleotides 3,874-3,892. The nucleotide numbers refer to the apo $E$ gene sequence (21).

The cloned apo E gene-Sac I fragments from the propositus and genomic DNA from nine family members and three control subjects were amplified by the polymerase chain reaction technique using the DNA amplification reagent kit (Perkin-Elmer Cetus, Emeryville, CA) and an automated thermal cycler (Perkin-Elmer Cetus). The DNA was amplified using primers PCRE1 (nucleotides 3,616-3,637 of the apo E gene coding strand [21]) and PCRE2 (nucleotides 3,914-3,893 of the apo $\mathrm{E}$ gene noncoding strand [21]). The conditions optimized for apo $\mathrm{E}$ were 40 cycles of denaturation for $2 \mathrm{~min}$ at $96^{\circ} \mathrm{C}$, annealing for $1.5 \mathrm{~min}$ at $62^{\circ} \mathrm{C}$, and extension for $2 \mathrm{~min}$ at $72^{\circ} \mathrm{C} \mathrm{(25).} \mathrm{The}$ amplified DNA was denatured and applied to nitrocellulose acetate membranes using a slot blot apparatus (Schleicher \& Schuell). The baked $\left(80^{\circ} \mathrm{C}\right)$ membranes were prehybridized for $1 \mathrm{~h}$ at $58^{\circ} \mathrm{C}$ in $5 \times$ Denhardt's $(5 X=0.1 \%$ Ficoll, $0.1 \%$ polyvinylpyrrolidone, $0.1 \% \mathrm{BSA})$, $10 \mathrm{mM}$ EDTA (pH 8.0), $0.5 \%$ SDS with $250 \mu \mathrm{g}$ of tRNA/ml of buffer, and then were hybridized overnight at $58^{\circ} \mathrm{C}$ with the appropriate labeled probes in $5 \times$ Denhardt's, $0.9 \mathrm{M} \mathrm{NaCl}, 0.09 \mathrm{M}$ Tris $\cdot \mathrm{HCl}(\mathrm{pH}$ 8.0), $6 \mathrm{mM}$ EDTA, $0.1 \%$ SDS with $250 \mu \mathrm{g}$ of $\mathrm{tRNA} / \mathrm{ml}$ of buffer. The membranes were washed twice for $5 \mathrm{~min}$ in $0.15 \mathrm{M} \mathrm{NaCl}, 15 \mathrm{mM} \mathrm{Na}$ citrate, $0.1 \%$ SDS at room temperature, and for $2 \mathrm{~min}$ in $15 \mathrm{mM} \mathrm{NaCl}$, $1.5 \mathrm{mM} \mathrm{Na}$ citrate, $0.1 \% \mathrm{SDS}$ at $65^{\circ} \mathrm{C}$ for the Arg- $112,63^{\circ} \mathrm{C}$ for the Cys- $112,59^{\circ} \mathrm{C}$ for the Arg- $142,57^{\circ} \mathrm{C}$ for the Cys- 142 , and $59^{\circ} \mathrm{C}$ for the Arg-158 probes, respectively. The washed membranes were then subjected to autoradiography.

\section{Results}

Structure of the variant apo E. Apo E was purified from the lipoproteins of the propositus (subject II-1, Fig. 1). The protein migrated in the E3 position upon isoelectric focusing; however, all the apo E shifted to the $\mathrm{E} 4$ position after cysteamine 


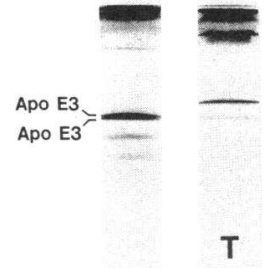

Figure 2. Isoelectric focusing ( $\mathrm{pH} \mathrm{4-6)} \mathrm{of}$ apo-VLDL from the propositus of the A. family. The cathode is at the top and the anode is at the bottom. In the left lane, there are two bands focusing in the $\mathrm{E} 3$ position. In the right lane, the apo-VLDL were cysteamine-treated $(T)$, causing the apo E3 to shift in position one positive charge, indicating the presence of one cysteine residue.

treatment (Fig. 2) (10), indicating the presence of one residue of cysteine. The untreated apo E (Fig. 2, left ) appeared as two bands, barely distinguishable from one another, with approximately equal intensity. These results, including the isoelectric focusing doublet, confirm the observations of Havel et al. (15), who also demonstrated that the more anionic component of the apo $E$ doublet cofocused with normal apo E3. The cysteine content of the apo $\mathrm{E}$ was confirmed by amino acid analysis, which gave 1.06 and 1.09 residues per molecule (determined as cysteic acid on two separate apo E preparations). No compositional differences between normal apo $\mathrm{E} 3$ and the apo $\mathrm{E}$ of the propositus were apparent (not shown).

The apo $\mathrm{E}$ was further analyzed by peptide sequencing. The large $\mathrm{CNBr}$ peptide corresponding to residues $126-218$ of apo $\mathrm{E}$ was isolated by gel chromatography and subjected to partial sequence analysis. At cycle 17, which corresponds to apo $E$ residue 142 , the arginine normally occurring at this position was present in only about half the expected amount, based on the repetitive yields of other arginines present in the peptide (Fig. 3). Although no other amino acid was detected at this position, amino acid analysis of this peptide indicated a partial residue of cysteine $(0.59$ and 0.56 residues per peptide molecule, determined as cysteic acid on two separate preparations). These results suggested that there were two forms of apo

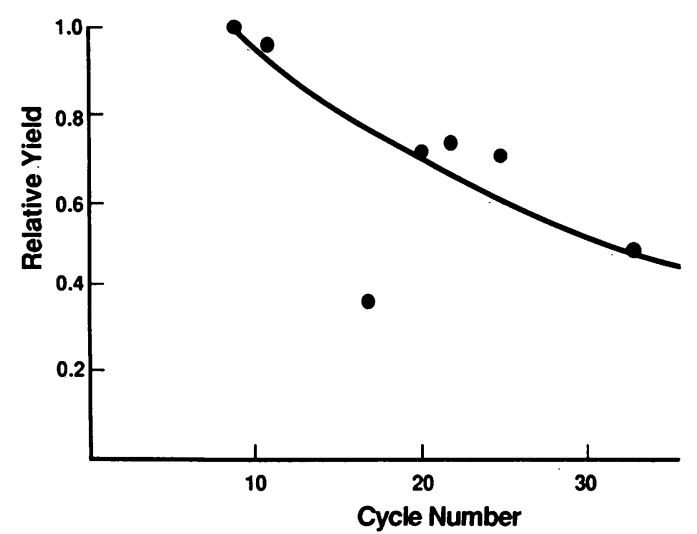

Figure 3. Partial sequence analysis of the largest $\mathrm{CNBr}$ peptide (residues 126-218) of apo $\mathrm{E}$ from the propositus of the A. family. The relative yields of the phenylthiohydantoin derivative of arginine, which occurs in normal apo E3 at cycles $9,11,17,20,22,25$, and 33 of this peptide, are normalized to the arginine yield at cycle 9 . The results are the average of separate determinations on two peptide preparations. The solid line represents a hypothetical $97 \%$ repetitive yield. The yield of arginine at cycle 17 , corresponding to residue 142 in apo $\mathrm{E}$, is significantly lower than that of the other arginine residues.
Table I. Composition and Sequence of the Apo E Tryptic Peptide (Residues 137-143) Containing the Cysteine Substitution at Residue 142

\begin{tabular}{|c|c|c|c|c|c|c|c|c|}
\hline Composition & & 1.8 & 0.9 & 1.2 & 1.0 & & $0.5^{*}$ & 1.2 \\
\hline Sequence & & Leu & Ala & Ser & His & Leu & Cys & - Lys \\
\hline Sequence cycle & 0 & 1 & 2 & 3 & 4 & 5 & 6 & 7 \\
\hline $\mathrm{nmol}$ & 48 & 19.3 & 20.2 & 7.6 & 5.1 & 18.7 & 10.3 & 7. \\
\hline Carryover (\%) & - & 10 & 6 & 18 & ND & 18 & 12 & 38 \\
\hline
\end{tabular}

Yield 28\%; mobility at pH $6.4=+0.27$, relative to lysine $=+1.00$; mobility of the normal peptide (residues 137-142) at $\mathrm{pH} 6.4$ $=+0.62(11)$.

* Determined as carboxymethylcysteine; a separate preparation of the peptide from noncarboxymethylated protein gave a cysteine value of 0.8 , determined as cysteic acid.

E, one having arginine at residue 142 and another having cysteine at this position.

The heterogeneity at residue 142 was confirmed by an analysis of tryptic peptides of carboxymethylated apo E. After the tryptic peptides were separated by high-voltage paper electrophoresis, a peptide corresponding to residues 137-142 was recovered in $22 \%$ yield and found to be identical in structure and properties to the peptide from normal apo E3 (not shown). A unique tryptic peptide corresponding to residues 137-143 was recovered in $28 \%$ yield (Table I). This peptide had no arginine, but instead contained cysteine at the position corresponding to residue 142; the peptide terminated with the normally occurring Lys-143 (Table I). These peptide analyses also indicated that the two forms of the protein were present in approximately equal amounts.

Because each of the two forms of apo $E$ must have one cysteine residue, it was likely that one was normal apo E3 with cysteine at residue 112 and arginine at residue 142, and the other a new variant (also phenotypically apo E3) with cysteine at residue 142 and arginine at residue 112 . This was confirmed by analyzing the apo $\mathrm{E}$ gene from the propositus of the $\mathrm{A}$. family (subject II-1). A genomic DNA library was prepared and the appropriate apo E gene fragment (i.e., one including DNA sequences corresponding to residues 112 and 142 of the protein sequence) was selected as described in Methods. Five independent clones were examined by DNA sequencing. The sequence of four clones was identical to normal apo E3, whereas the fifth had an arginine at residue 112 and a cysteine at residue 142 as a result of its difference at two nucleotide positions (Fig. 4). Thus, the propositus is heterozygous for two different apo E alleles: one allele codes for normal apo E3, while the other codes for an apo E3 that differs at two sites from normal apo E3, residues 112 and 142.

Genetics of apo $E$ in the A. family. Members of four generations of the A. family were screened in order to understand the transmission of the variant apo E3 and its association with type III hyperlipoproteinemia. DNA was prepared from nine members of the family, amplified, and subjected to slot blot analysis using synthetic oligonucleotide probes designed to detect the sequence differences between the two apo $\mathrm{E}$ alleles found in the propositus. The DNA of all nine A. family members was positive for both the Cys-112 and Arg-142 probes (not shown), indicating the presence of at least one normal apo E3 allele. Furthermore, A. family members II-2, 
$\begin{array}{cccc}\text { Pst I } & & & \text { Pst I } \\ 97 & 112 & 142 & 155\end{array}$

Allele 1 ......Met Glu Asp Val Cys Gly Arg Leu Val.....Ala Ser His Leu Arg Lys Leu Arg Lys..... (normal E3) ......ATG GAG GAC GTG TGC GGC CGC CTG GTG..... GCC TCC CAC CTG CGC AAG CTG CGT AAG.....

Allele $2 \ldots . .$. ATG GAG GAC GTG CGC GGC CGC CTG GTG..... GCC TCC CAC CTG TGC AAG CTG CGT AAG..... (variant E3)..... Met Glu Asp Val Arg Gly Arg Leu Val.....Ala Ser His Leu Cys Lys Leu Arg Lys..... 112
Figure 4. Partial sequences of the two apo E alleles from the propositus of the A. family. Only the sequences in the region of the differences between the Pst I fragments are shown. The arrows denote the two nucleotide differences between the alleles that cause amino acid differences at apo $\mathrm{E}$ residues 112 and 142 .
III-1, III-5, and IV-1 are homozygous for normal apo E3 because their DNA was unreactive to both the Arg-112 and Cys-142 probes (Fig. 5). In contrast, the DNA of subjects I-1, III-2, III-3, III-4, and IV-2 was reactive to both of these probes (Fig. 5). Therefore, these subjects are heterozygous, having both the normal apo E3 allele and the variant apo E3 allele. All of these latter subjects except subject IV-2 had been identified by Havel et al. (15) as having type III hyperlipoproteinemia. Subject IV-2, now 6 yr of age, has been hypercholesterolemic and hypertriglyceridemic since he was $2 \mathrm{yr}$ of age (Bersot,

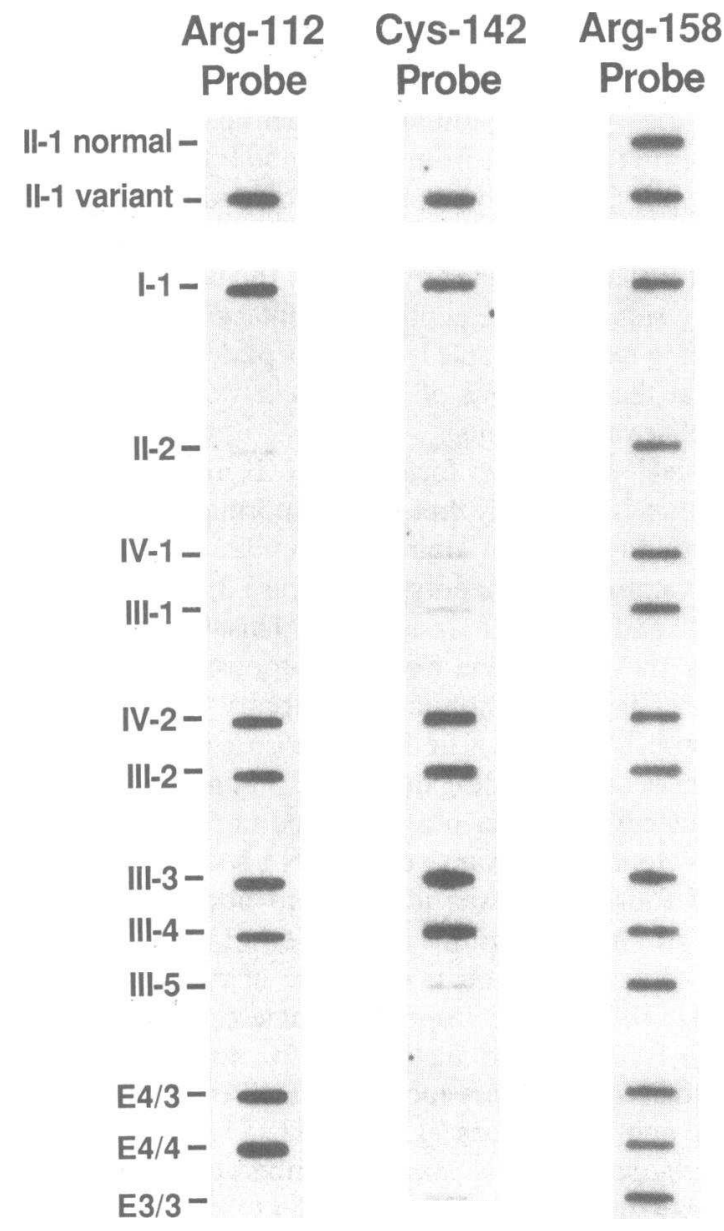

Figure 5. Presence of the apo E variant allele in the A. family. DNA was prepared from each subject, amplified, and hybridized with either the Arg-112 (left), Cys-142 (center), or Arg-158 (right) oligonucleotide probes as described in Methods. At the top are the two cloned apo E alleles from the propositus (II-1), followed by the amplified genomic DNA from nine family members (designations as in Fig. 1). At the bottom is amplified genomic DNA from three control subjects (E4/3, E4/4, E3/3 phenotypes). The Arg-158 probe was used to monitor the extent of amplification.
T. P., unpublished observation). Therefore, there appears to be an absolute association of the variant apo E3 with type III hyperlipoproteinemia. These findings are summarized in Table II along with other information on A. family members.

Receptor binding activity of the variant apo E3. The apo E from three affected family members (II-1, III-3, and III-4) was isolated by gel filtration chromatography and subjected to receptor binding analysis in an in vitro assay (16). Because the normal and the variant apo $E$ have an identical amino acid composition, molecular weight, and charge, attempts to separate them were unsuccessful, even with isoelectric focusing using extremely shallow pH gradients. As shown in Fig. 6, the apo E.DMPC complexes made from the apo $\mathrm{E}$ of these three affected family members were all defective, and to about the same degree, in binding to the apo $B, E(L D L)$ receptor on human fibroblasts, unlike normal apo E3, which was used as the control. Based on the $50 \%$ competition point from a logitlog plot of the binding data in Fig. 6, the apo E from subjects II- 1 , III-3, and III-4 displayed 20,19 , and $26 \%$ of normal binding, respectively. Unlike some other apo $E$ variants that have cysteine substitutions, treatment of this defective apo E3 with cysteamine did not increase its activity (not shown).

\section{Discussion}

These results have demonstrated that $\mathrm{A}$. family members with type III hyperlipoproteinemia each have one allele that codes for an unusual variant of apo E. This apo E3 isoform differs from normal apo E3 at two positions: arginine is present at

Table II. Clinical and Genetic Summary of the A. Family

\begin{tabular}{llrlccc}
\hline Subject & Age/sex & \multicolumn{1}{c}{ TG* $^{*}$} & TC $^{\ddagger}$ & $\begin{array}{c}\text { Type III } \\
\text { hyperlipoproteinemia } \\
\text { (incl. } \beta \text {-VLDL) }\end{array}$ & $\begin{array}{c}\text { Apo E variant } \\
\text { (Arg-1 12, Cys-142) }\end{array}$ \\
\hline I-1 $^{\S}$ & $73 / \mathrm{F}$ & 222 & 259 & Yes & + \\
II-1" $^{\|}$ & $52 / \mathrm{F}$ & 129 & 298 & Yes & + \\
II-2 & $52 / \mathrm{M}$ & 119 & 216 & No & - \\
III-1 & $28 / \mathrm{F}$ & 90 & 284 & No & - \\
III-2 & $27 / \mathrm{M}$ & 852 & 697 & Yes & + \\
III-3 & $24 / \mathrm{F}$ & 264 & 285 & Yes & + \\
III-4 & $23 / \mathrm{F}$ & 316 & 525 & Yes & + \\
III-5 & $19 / \mathrm{M}$ & 118 & 361 & No & - \\
IV-1 & $7 / F$ & 67 & 290 & No & - \\
IV-2 & $6 / \mathrm{M}$ & 231 & 414 & Yes & + \\
& & & & & &
\end{tabular}

* Total plasma triglycerides (TG) in milligrams/deciliter, determined in July 1987.

₹ Total plasma cholesterol (TC) in milligrams/deciliter, determined in July 1987.

$\S$ On gemfibrozil therapy at time of sampling.

"On nicotinic acid therapy at time of sampling. 


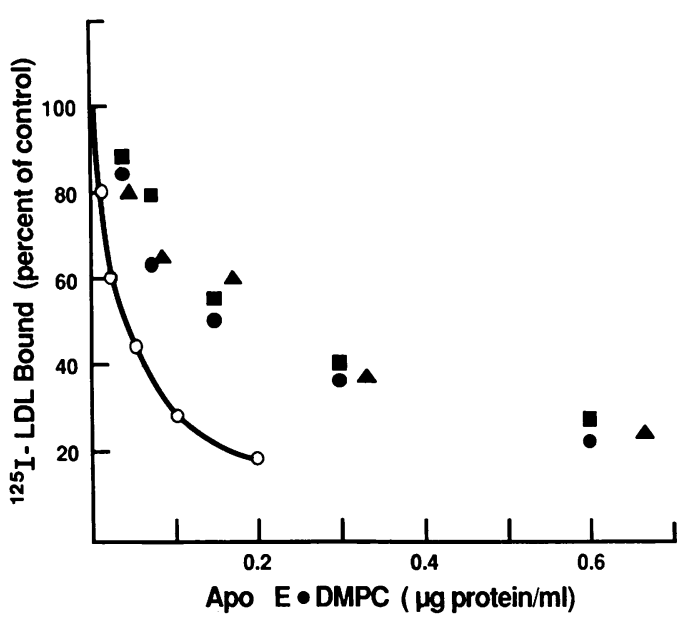

Figure 6. Receptor binding activity of apo E from three affected members of the A. family, as assessed in a competition assay. The apo E - DMPC complexes were mixed at various concentrations with $2 \mu \mathrm{g}$ of ${ }^{125} \mathrm{I}-\mathrm{LDL}$ and incubated with cultured human fibroblasts on $35-\mathrm{mm}$ culture dishes for $4 \mathrm{~h}$ at $4^{\circ} \mathrm{C}$. The $100 \%$ control value for ${ }^{125} \mathrm{I}-\mathrm{LDL}$ was $97 \mathrm{ng}$ bound/mg of cellular protein. $\Delta$, apo $\mathrm{E}$ from sub-

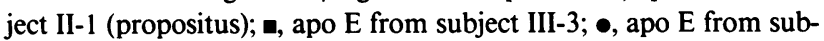
ject III-4; O, apo E3/3 control.

residue 112 instead of the usual cysteine, and cysteine is present at residue 142 instead of the usual arginine. Arg- 112 is present in apo E4, but apo E4 has arginine at residue 142 and does not contain cysteine. Because this apo E3 variant differs from apo E4 at only one position (residue 142), it is likely that the variant arose as a result of a point mutation in an allele for apo E4.

The mutation at nucleotide 3,835 that changes the codon from CGC (Arg-142) to TGC (Cys-142) is an example of a mutational "hot spot" in a CpG dinucleotide sequence $(26$, 27). Cytosine residues $5^{\prime}$ to guanine are methylated in mammalian DNA. This methylation leads to an increased frequency of cytosine deamination and cytosine-to-thymine transitions. Perhaps as a result of this increased frequency of mutation, the $\mathrm{CpG}$ dinucleotide occurs at a frequency that is only $37 \%$ of that expected by chance (28). Codons containing a $\mathrm{CpG}$ dinucleotide are used less frequently than other degenerate codons for the same amino acid (29). For example, in the case of the six possible arginine codons, the four containing CpG, i.e., CGA, CGC, CGG, and CGT, occur at a combined frequency of $28.7 / 1,000$ codons, while AGA and AGG together account for $21.1 / 1,000$ codons in a total of 3,681 human genes (29). In this respect the apo E gene is very unusual: 33 of the 34 arginine codons in the E3 gene contain the CpG sequence (19). Furthermore, the mutations that distinguish E3 from E4 and E2 from E3 are both of the same type as the residue 142 mutation. Because the $\mathrm{CpG}$ dinucleotide is 10 times more likely to mutate than any other dinucleotide (26), it is a distinct possibility that mutations will be found at other arginine positions in human apo $\mathrm{E}$.

The genetic analysis of apo $\mathrm{E}$ in this family proves the transmission of the gene for this variant through four generations. All the subjects with this variant are heterozygous for apo E. In spite of the presence of normal apo E3 in these subjects, all individuals with the variant apo E3 have $\beta$-VLDL and other symptoms characteristic of type III hyperlipopro- teinemia. The transmission of this disorder is unusual in that the disorder appears to be a dominant trait; typical type III hyperlipoproteinemia results from the inheritance of two alleles for apo E2 and therefore appears to be a recessive trait. The absolute correlation between the presence of the variant apo E3 and the occurrence of type III hyperlipoproteinemia in this family strongly suggests that this characteristic is dominant in this case (Table II).

The clinical findings in the most recent survey of the A. family (Table II) are consistent with those described by Havel et al. in 1983 (15). The presence of $\beta$-VLDL in affected subjects has been confirmed by agarose gel analysis of $d<1.006$ $\mathrm{g} / \mathrm{ml}$ lipoproteins. The current study extends the analysis to the fourth generation of the A. family. Subject IV-2, now $6 \mathrm{yr}$ of age, exhibits the disorder, and his sibling, now 4 yr of age but not studied on the most recent occasion, was found to be hyperlipidemic at age 2 (Bersot, T. P., unpublished observation). The affected members of the third generation were hyperlipidemic even as teenagers (15). The extremely early occurrence of hyperlipidemia in this family is highly unusual for type III subjects.

Several unaffected members of the family, although they do not have $\beta$-VLDL or the apo E3 variant, appear to be hypercholesterolemic (subjects III-1, III-5, and IV-1 in Table II). No cause, genetic or otherwise, has yet been ruled out, although there is some evidence that familial hypercholesterolemia is not involved. Fibroblasts from the propositus and her mother bind both autologous and heterologous LDL normally, indicating the absence of an LDL receptor defect (Bersot, T. P., unpublished observations). Also, none of the family members without type III hyperlipoproteinemia had any of the clinical characteristics of familial hypercholesterolemia (e.g., tendinous xanthomas). However, it is likely that there is a separate defect in lipid metabolism in this family in addition to type III hyperlipoproteinemia. Perhaps there is a correlation of this other proposed defect with the very early expression of type III in these subjects or with the apparently dominant transmission of type III hyperlipoproteinemia in this family.

The protein studies indicate that the VLDL of affected subjects contain approximately equivalent amounts of normal and variant apo E3. Defective apo $E$ variants might be expected to accumulate in the plasma relative to their normal counterparts. However, in most E3/2 subjects this does not appear to be the case (14). In contrast, the situation is markedly different in two other occurrences of rare apo $E$ variants and type III hyperlipoproteinemia: the E2-Christchurch variant (30) predominates by $\sim 5: 1$ over the other apo $E$ gene product, and the E3-Leiden variant (31) predominates even more over its normal apo E counterpart. In both these cases, the rare apo $\mathrm{E}$ variant is defective in binding to lipoprotein receptors. Assessing the situation in the subjects described herein is not a simple matter. The apo E3 variant is apo E4-like in that it contains arginine at residue 112. It is known that apo E4 distributes preferentially to VLDL (32). The combination of this factor with the receptor binding defect (see below) might be expected to cause the apo E3 variant to predominate over normal apo E3 in VLDL. That this does not occur suggests that some compensatory mechanism might be involved.

The apo E3 variant described in this report is also defective in its interaction with the apo $\mathrm{B}, \mathrm{E}(\mathrm{LDL})$ receptor, as determined by a competition assay of apo E $\cdot$ DMPC complexes with ${ }^{125}$ I-labeled LDL in cultured normal human fibroblasts 
(Fig. 6). In a rat liver perfusion study using similar complexes, Havel et al. (15) were unable to detect a significant difference between the uptake of normal apo $E$ and that of apo $E$ from the A. family. The discrepancy between our results and those of Havel et al. may be due to the differing sensitivities of the two assays to the presence of normal apo E3. Because the apo $E$ used in our binding study comprised normal and variant forms of apo E3 that were present in equivalent amounts, the actual binding activity of the apo E3 variant could not be determined directly. However, it is possible to estimate the activity of this variant from other data. Mixtures containing equal amounts of active and inactive apo $\mathrm{E}$ do not have a binding activity of $50 \%$ of normal. In a study of apo E D DMPC complexes of mixtures of normal and chemically inactivated apo E, Pitas et al. (33) found that a 1:1 mixture had an activity about $29 \%$ of that of control complexes. Likewise, Weisgraber et al. (34) found that an apo $E$ isoform by itself had $4 \%$ activity, whereas $\mathbf{a} \sim 1: 1$ mixture of this isoform and normal apo E3 had $22-28 \%$ activity. The calculated activity of the apo E mixture from three A. family members was $19-26 \%$. Since these activities are similar to those found in both the Pitas et al. and Weisgraber et al. studies, in which mixtures containing equal amounts of normal apo E3 and a severely defective apo E (4\% or less activity) were used, it is likely that the apo E3 variant of the A. family is also severely defective, and probably has only a few percent of the receptor binding activity of normal apo E3. Therefore, the situation in the A. family is similar to that in other type III subjects in that a mutated form of apo $E$ that is defective in binding to lipoprotein receptors is the primary genetic defect and is probably responsible, at least in part, for the expression of type III hyperlipoproteinemia in these subjects.

The mutation in this variant that is responsible for the defective interaction with receptors is undoubtedly the cysteine-for-arginine substitution at residue 142 . The other substitution, arginine-for-cysteine at residue 112 , also occurs in apo E4, which exhibits the same receptor binding activity as apo E3 (12). Position 142 in the apo E sequence occurs in a putative helical segment that is greatly enriched in basic amino acids (11). It has already been shown that single substitutions of neutral for basic amino acid residues in this segment have an adverse effect on receptor binding activity (35), and this central portion of the apo $\mathrm{E}$ molecule has also been shown by other methods to be critical for its receptor binding function $(36,37)$. Therefore, the results of the current study underscore the importance of Arg-142 in maintaining normal receptor binding. In previous studies, the binding activity of apo $\mathrm{E}$ variants with a cysteine substitution at either residue 145 or 158 could be enhanced by cysteamine treatment $(12,38)$, which converts cysteine residues to positively charged, lysinelike analogues (10). The fact that cysteamine treatment did not enhance the binding activity in the present case may imply a difference in the way Arg-142 is involved in receptor interaction compared with Arg-145 or Arg-158. However, assessing this possibility will require that the variant apo E3 first be separated from the normal apo E3, or that the variant apo E3 be produced separately by recombinant DNA techniques.

\section{Acknowledgments}

The authors thank Dr. David A. Chappell for performing the agarose gel analysis of the lipoproteins, Kay S. Arnold for performing the receptor binding ássays, James $\mathrm{X}$. Warger and Charles Benedict for graphic art, $\mathrm{Al}$ Averbach and Sally Gullatt Seehafer for editorial assistance, and Kerry Humphrey for manuscript preparation.

\section{References}

1. Brown, M. S., J. L. Goldstein, and D. S. Fredrickson. 1983. Familial type 3 hyperlipoproteinemia (dysbetalipoproteinemia). In The Metabolic Basis of Inherited Disease. J. B. Stanbury, J. B. Wyngaarden, D. S. Fredrickson, J. L. Goldstein, and M. S. Brown, editors. 5th ed. McGraw-Hill Book Co., New York. 655-671.

2. Fainaru, M., R. W. Mahley, R. L. Hamilton, and T. L. Innerarity. 1982. Structural and metabolic heterogeneity of $\beta$-very low density lipoproteins from cholesterol-fed dogs and from humans with type III hyperlipoproteinemia. J. Lipid Res. 23:702-714.

3. Kane, J. P., G. C. Chen, R. L. Hamilton, D. A. Hardman, M. J. Malloy, and R. J. Havel. 1983. Remnants of lipoproteins of intestinal and hepatic origin in familial dysbetalipoproteinemia. Arteriosclerosis. 3:47-56.

4. Havel, R. J., and J. P. Kane. 1973. Primary dysbetalipoproteinemia: predominance of a specific apoprotein species in triglyceriderich lipoproteins. Proc. Natl. Acad. Sci. USA. 70:2015-2019.

5. Mahley, R. W., and T. L. Innerarity. 1983. Lipoprotein receptors and cholesterol homeostasis. Biochim. Biophys. Acta. 737:197-222.

6. Mahley, R. W., and B. Angelin. 1984. Type III hyperlipoproteinemia: recent insights into the genetic defect of familial dysbetalipoproteinemia. Adv. Intern. Med. 29:385-411.

7. Zannis, V. I., P. W. Just, and J. L. Breslow. 1981. Human apolipoprotein $\mathrm{E}$ isoprotein subclasses are genetically determined. $\mathrm{Am}$. J. Hum. Genet. 33:11-24.

8. Zannis, V. I., and J. L. Breslow. 1981. Human very low density lipoprotein apolipoprotein $\mathrm{E}$ isoprotein polymorphism is explained by genetic variation and posttranslational modification. Biochemistry. 20:1033-1041.

9. Zannis, V. I., J. L. Breslow, G. Utermann, R. W. Mahley, K. H. Weisgraber, R. J. Havel, J. L. Goldstein, M. S. Brown, G. Schonfeld, W. R. Hazzard, and C. Blum. 1982. Proposed nomenclature of apoE isoproteins, apoE genotypes, and phenotypes. J. Lipid Res. 23:911914.

10. Weisgraber, K. H., S. C. Rall, Jr., and R. W. Mahley. 1981. Human $\mathrm{E}$ apoprotein heterogeneity: cysteine-arginine interchanges in the amino acid sequence of the apo-E isoforms. J. Biol. Chem. 256:9077-9083.

11. Rall, S. C., Jr., K. H. Weisgraber, and R. W. Mahley. 1982. Human apolipoprotein E: the complete amino acid sequence. J. Biol. Chem. 257:4171-4178.

12. Weisgraber, K. H., T. L. Innerarity, and R. W. Mahley. 1982. Abnormal lipoprotein receptor-binding activity of the human $\mathrm{E}$ apoprotein due to cysteine-arginine interchange at a single site. J. Biol. Chem. 257:2518-2521.

13. Utermann, G. 1985. Genetic polymorphism of apolipoprotein E: impact on plasma lipoprotein metabolism. In Diabetes, Obesity and Hyperlipidemias III. G. Crepaldi, A. Tiengo, and G. Baggio, editors. Excerpta Medica, Amsterdam. 1-28.

14. Utermann, G. 1982. Apolipoprotein $\mathrm{E}$ (role in lipoprotein metabolism and pathophysiology of hyperlipoproteinemia type III). Ric. Clin. Lab. 12:23-33.

15. Havel, R. J., L. Kotite, J. P. Kane, P. Tun, and T. Bersot. 1983. Atypical familial dysbetalipoproteinemia associated with apolipoprotein phenotype E3/3. J. Clin. Invest. 72:379-387.

16. Innerarity, T. L., R. E. Pitas, and R. W. Mahley. 1986. Lipoprotein-receptor interactions. Methods Enzymol. 129:542-566.

17. Maniatis, T., E. F. Fritsch, and J. Sambrook. 1982. Molecular Cloning. A Laboratory Manual. Cold Spring Harbor Laboratory, Cold Spring Harbor, NY.

18. Feinberg, A. P., and B. Vogelstein. 1983. A technique for radiolabeling DNA restriction endonuclease fragments to high specific activity. Anal. Biochem. 132:6-13. 
19. McLean, J. W., N. A. Elshourbagy, D. J. Chang, R. W. Mahley, and J. M. Taylor. 1984. Human apolipoprotein E mRNA: cDNA cloning and nucleotide sequencing of a new variant. J. Biol. Chem. 259:6498-6504.

20. Southern, E. M. 1979. Gel electrophoresis of restriction fragments. Methods Enzymol. 68:152-176.

21. Paik, Y.-K., D. J. Chang, C. A. Reardon, G. E. Davies, R. W. Mahley, and J. M. Taylor. 1985. Nucleotide sequence and structure of the human apolipoprotein E gene. Proc. Natl. Acad. Sci. USA. 82:3445-3449.

22. Sanger, F., S. Nicklen, and A. R. Coulson. 1977. DNA sequencing with chain-terminating inhibitors. Proc. Natl. Acad. Sci. USA. 74:5463-5467.

23. Goossens, M., and Y. Y. Kan. 1981. DNA analysis in the diagnosis of hemoglobin disorders. Methods Enzymol. 76:805-817.

24. Maxam, A. M., and W. Gilbert. 1980. Sequencing end-labeled DNA with base-specific chemical cleavages. Methods Enzymol. 65:499-560.

25. Weisgraber, K. H., Y. M. Newhouse, and R. W. Mahley. 1988. Apolipoprotein $\mathrm{E}$ genotyping using the polymerase chain reaction and allele-specific oligonucleotide probes. Biochem. Biophys. Res. Commun. 157:1212-1217.

26. Barker, D., M. Schafer, and R. White. 1984. Restriction sites containing $\mathrm{CpG}$ show a higher frequency of polymorphism in human DNA. Cell. 36:131-138.

27. Youssoufian, H., H. H. Kazazian, Jr., D. G. Phillips, S. Aronis, G. Tsiftis, V. A. Brown, and S. E. Antonarakis. 1986. Recurrent mutations in haemophilia A give evidence for $\mathrm{CpG}$ mutation hotspots. Nature (Lond.). 324:380-382.

28. Nussinov, R. 1981. Eukaryotic dinucleotide preference rules and their implications for degenerate codon usage. J. Mol. Biol. 149:125-131.

29. Aota, S., T. Gojobori, F. Ishibashi, T. Maruyama, and T. Ikemura. 1988. Codon usage tabulated from the GenBank Genetic Sequence Data. Nucleic Acids Res. 16(Suppl):r315-r402.
30. Wardell, M. R., S. O. Brennan, E. D. Janus, R. Fraser, and R. W. Carrell. 1987. Apolipoprotein E2-Christchurch (136 Arg $\rightarrow$ Ser). New variant of human apolipoprotein $E$ in a patient with type III hyperlipoproteinemia. J. Clin. Invest. 80:483-490.

31. Havekes, L., E. de Wit, J. G. Leuven, E. Klasen, G. Utermann, W. Weber, and U. Beisiegel. 1986. Apolipoprotein E3-Leiden: a new variant of human apolipoprotein $\mathrm{E}$ associated with familial type III hyperlipoproteinemia. Hum. Genet. 73:157-163.

32. Gregg, R. E., L. A. Zech, E. J. Schaefer, D. Stark, D. Wilson, and H. B. Brewer, Jr. 1986. Abnormal in vivo metabolism of apolipoprotein $\mathrm{E}_{4}$ in humans. J. Clin. Invest. 78:815-821.

33. Pitas, R. E., T. L. Innerarity, and R. W. Mahley. 1980. Cell surface receptor binding of phospholipid - protein complexes containing different ratios of receptor-active and -inactive $\mathrm{E}$ apoprotein. $J$. Biol. Chem. 255:5454-5460.

34. Weisgraber, K. H., S. C. Rall, Jr., T. L. Innerarity, R. W. Mahley, T. Kuusi, and C. Ehnholm. 1984. A novel electrophoretic variant of human apolipoprotein $\mathrm{E}$. Identification and characterization of apolipoprotein E1. J. Clin. Invest. 73:1024-1033.

35. Mahley, R. W., T. L. Innerarity, S. C. Rall, Jr., and K. H. Weisgraber. 1984. Plasma lipoproteins: apolipoprotein structure and function. J. Lipid Res. 25:1277-1294.

36. Innerarity, T. L., E. J. Friedlander, S. C. Rall, Jr., K. H. Weisgraber, and R. W. Mahley. 1983. The receptor-binding domain of human apolipoprotein E: binding of apolipoprotein E fragments. $J$. Biol. Chem. 258:12341-12347.

37. Weisgraber, K. H., T. L. Innerarity, K. J. Harder, R. W. Mahley, R. W. Milne, Y. L. Marcel, and J. T. Sparrow. 1983. The receptor-binding domain of human apolipoprotein E: monoclonal antibody inhibition of binding. J. Biol. Chem. 258:12348-12354.

38. Rall, S. C., Jr., K. H. Weisgraber, T. L. Innerarity, and R. W. Mahley. 1982. Structural basis for receptor binding heterogeneity of apolipoprotein E from type III hyperlipoproteinemic subjects. Proc. Natl. Acad. Sci. USA. 79:4696-4700. 